\title{
What is the optimal therapeutic protocol for using a durable left ventricular assist device in the near future of a developing country?
}

\author{
Jun Ho Lee ${ }^{1}$, Yang Hyun $\mathrm{Cho}^{2}$ \\ ${ }^{1}$ Department of Thoracic and Cardiovascular Surgery, Hanyang University Seoul Hospital, Hanyang University College of Medicine, Seoul, \\ Republic of Korea; ${ }^{2}$ Department of Thoracic and Cardiovascular Surgery, Samsung Medical Center, Sungkyunkwan University School of Medicine, \\ Seoul, Republic of Korea \\ Correspondence to: Yang Hyun Cho, MD, PhD. Department of Thoracic and Cardiovascular Surgery, Samsung Medical Center, Sungkyunkwan \\ University School of Medicine, 81 Irwon-ro, Gangnam-gu Seoul 06351, Republic of Korea. Email: mdcho95@gmail.com. \\ Response to: Imamura T. Optimal therapeutic strategy using durable left ventricular assist device in Korea. J Thorac Dis 2021;13:2565-6.
}

Submitted Feb 27, 2021. Accepted for publication Mar 04, 2021.

doi: $10.21037 /$ jtd-21-338

View this article at: http://dx.doi.org/10.21037/jtd-21-338

Left ventricular assist device (LVAD) implantation as a bridge to candidacy or destination therapy for end-stage heart failure is desirable to improve the survival rate of diseased patients (1). The letter titled "Optimal therapeutic strategy using durable left ventricular assist device in Korea," raises several impressive questions, which we will describe herein (2).

Our team, along with other Korean colleagues, had continued to challenge LVAD implantation in such diseased patients with relative contraindications. Thus, in September 2018, the Korean national insurance began to cover LVAD for both bridge-to-transplantation and destination therapy (1). As of December 2020, the total number of patients with durable LVAD implantation at our institution has exceeded 80. We believe that this experience may have led to improved clinical outcomes.

Despite encountering multiple successful cases, we have also experienced diverse short-term and long-term complications after LVAD. We perform echocardiographic and hemodynamic ramp tests with/without exercise on all patients before discharge. However, we believe that the most optimal revolutions per minute (rpm) may be the one during which the patient feels the best. We call it "the clinical ramp test," which entails the adjustment of rpm according to the symptoms, signs, and dynamic pump parameters of the patient. Currently we are comparing the clinical ramp test with laboratory ramp tests. Bleeding complications in organs, including the gastrointestinal system and the brain, are major concerns in our center. We also suspect that there may be genetic or racial differences between the Asian and Western population (3-5). We hope that HeartMate 3 may reduce the incidence of bleeding complications.

Our team, along with other Korean colleagues, intends to establish a prospective multicenter registry with longterm follow-up in the near future.

\section{Acknowledgments}

Funding: None.

\section{Footnote}

Provenance and Peer Review: This article was commissioned by the editorial office, fournal of Thoracic Disease. The article did not undergo external peer review.

Conflicts of Interest: Both authors have completed the ICMJE uniform disclosure form (available at http://dx.doi. org/10.21037/jtd-21-338). Both authors have no conflicts of interest to declare.

Ethical Statement: The authors are accountable for all aspects of the work in ensuring that questions related to the accuracy or integrity of any part of the work are appropriately investigated and resolved. 
Open Access Statement: This is an Open Access article distributed in accordance with the Creative Commons Attribution-NonCommercial-NoDerivs 4.0 International License (CC BY-NC-ND 4.0), which permits the noncommercial replication and distribution of the article with the strict proviso that no changes or edits are made and the original work is properly cited (including links to both the formal publication through the relevant DOI and the license). See: https://creativecommons.org/licenses/by-nc-nd/4.0/.

\section{References}

1. Lee JH, Park I, Lee H, et al. Use of durable left ventricular assist devices for high-risk patients: Korean experience before insurance coverage. J Thorac Dis 2020;12:7236-44.

Cite this article as: Lee JH, Cho YH. What is the optimal therapeutic protocol for using a durable left ventricular assist device in the near future of a developing country? J Thorac Dis 2021;13(4):2567-2568. doi: 10.21037/jtd-21-338
2. Imamura T. Optimal therapeutic strategy using durable left ventricular assist device in Korea. J Thorac Dis 2021;13:2565-6.

3. Imamura $\mathrm{T}$, Ono $\mathrm{M}$, Kinugawa $\mathrm{K}$, et al. Hemocompatibility-related adverse events following HeartMate II left ventricular assist device implantation between Japan and United States. Medicina 2020;56:126.

4. Shen AY, Yao JF, Brar SS, et al. Racial/ethnic differences in the risk of intracranial hemorrhage among patients with atrial fibrillation. J Am Coll Cardiol 2007;50:309-15.

5. Mehta RH, Cox M, Smith EE, et al. Race/ethnic differences in the risk of hemorrhagic complications among patients with ischemic stroke receiving thrombolytic therapy. Stroke 2014;45:2263-9. 